\title{
Assessment of variations in benzene concentration produced from vehicles and gas stations in Tehran using GIS
}

\author{
F. Atabi - F. Moattar • N. Mansouri • \\ A. A. Alesheikh - S. A. H. Mirzahosseini
}

Received: 21 June 2012/ Accepted: 7 December 2012/Published online: 11 January 2013

(c) CEERS, IAU 2013

\begin{abstract}
This study investigates the variations of benzene concentration levels in district 1 , situated in the north part of Tehran, capital of Iran. Thirty-three stations in five categories, namely roadsides, busy roads, residential areas, traffic intersections, and the vicinity of gas stations, were monitored during the rush hours in the afternoon once a week over a period of 1 year. Accordingly, benzene concentration levels were measured and predicted by inverse distance weight model. The recorded benzene concentration levels were then compared with those reported in other parts of the world. According to the results, the annual concentration levels of benzene was $13.85 \mathrm{ppb}$ for roads with heavy traffic flow, $14.98 \mathrm{ppb}$ for traffic intersections, $29.01 \mathrm{ppb}$ for the vicinity of the gas stations, $3.26 \mathrm{ppb}$ for residential areas, and $9.97 \mathrm{ppb}$ for roadsides. The concentration of benzene in the vicinity of the gas station sampling point was higher than in the other stations, and at all locations was found to be so much more than the standard concentration levels (1.56 ppb) prescribed by Environmental Protection Agency for the ambient air quality. The results of the study revealed that the benzene concentration levels in Tehran are distinctly more than its standard level. This is mainly attributed to the poor quality of fuel and lack
\end{abstract}

F. Atabi - F. Moattar - N. Mansouri - A. A. Alesheikh ·

S. A. H. Mirzahosseini ( $\square)$

Department of Environment and Energy, Science

and Research Branch, Islamic Azad University,

P.O. Box 14515-775, Tehran, Iran

e-mail: mirzahosseini@gmail.com

A. A. Alesheikh

Department of GIS Engineering, Khajeh Nasir Toosi

University of Technology, Tehran, Iran of a standard system for controlling petrol vapors in the gas stations.

Keywords Air pollution - Volatile organic compounds . Traffic Photo ionization detector .

Inverse distance weight

\section{Introduction}

The air pollution due to transportation is one of the most important problems in Tehran, which has yet affected the development of many key projects, including transportation navigation projects (Abbaspour and Soltaninejad 2004). Tehran can be regarded as one of the most urbanized regions in the developing world, which is currently suffering from severe air pollution. Unfortunately, there are few quantitative studies in regard with the concentrations of volatile organic compounds (VOCs) in Tehran. This may be due to the dominant presence of a range of other pollutants, such as $\mathrm{NO}_{x}, \mathrm{SO}_{x}$, and particulate matter, which have overshadowed the role of one of the most hazardous VOCs like benzene in the air pollution studies. Vehicular traffic is the major source of benzene in the atmosphere. Approximately $80-90 \%$ of the benzene in the urban atmosphere has been estimated to be derived from automobile exhaustion (Perry and Gee 1993; Vlachokostas et al. 2011; Batterman et al. 2006; Guo et al. 2007; Han and Naeher 2006; Jafari and Ebrahimi 2007).

Generally, VOCs are toxic environmental pollutants and usually are monitored in metropolitan areas. They are present especially in high concentration as benzene in urban areas and many of them have adverse impacts on human health (Hsieh et al. 2006; Schifter et al. 2006; Khoder 2007; Karner et al. 2010; Som et al. 2007; Rao 
et al. 2008). Benzene is classified as a human carcinogen in category A, providing sufficient evidence to support the fundamental association between exposure and Benzene and cancer (IARC 2012; Theloke and Friedrich 2007; Official Journal of the European Communities L 313 2000).

In order to reduce benzene exposure levels in urban environments, European Commission set a maximum limit of $1.56 \mathrm{ppb}$ through Directive 2000/69 in 2010. Mean ambient air concentration of benzene in rural areas is about $0.32 \mathrm{ppb}$ and in urban areas the concentration of benzene is in the range 1.56-6.5 ppb (Theakston 2000). In Japan, the ambient air quality standard for benzene has been set to be $0.85 \mathrm{ppb}$ (Laowagul and Yoshizumi 2009). In conurbations, which are characterized by both high levels of population density and traffic-related air pollution, traffic is the most important source of ambient air benzene concentration (Colls and Micallef 1997; Bahrami and Edwards 2006)

Worldwide studies have shown a relation between benzene concentration and traffic flow and streets with high traffic flow have typically double the benzene concentration compared to streets with low traffic flow. Annual averages of benzene concentration have previously been measured in various European regions, as reported by Cocheo et al. (2000) IVL Swedish Environmental Research Institute and Skov et al. (2001). The annual average concentrations of benzene in metropolitans have ranged from a little ppb to more than $6.25 \mathrm{ppb}$ (Anabtawi et al. 1996). Benzene concentration in Mexico City has been reported to be $14.46 \mathrm{ppb}$ (Ortiz et al. 2002). In Milan, benzene concentration was observed to be $0.78-2 \mathrm{ppb}$ (Meinardi et al. 2008). In Bangkok, $1.81 \mathrm{ppb}$ was monitored as the average benzene concentration over 5 months (Laowagul and Yoshizumi 2009). In China, daily average benzene concentration was observed to be 3.6 ppb (Wang et al. 2010).

Recently with the rapid development of geographic information system (GIS), its application has been extended into many environmental research domains. Some researchers have employed GIS tools to account for the high spatial heterogeneity of local traffic emissions with simple exposure surrogates such as distance-weighted traffic density (Wilhelm and Ritz 2003). Obee et al. (1998) also applied a combination of mathematical modeling and GIS for estimation of residential risk from industrial air pollution in Mexico. Lin and Lin (2002) developed an integrated simulation system for traffic flow information, air pollution modeling, and utilizing GIS, which integrates a vehicle emission model, pollutant dispersion model, backward trajectory model, and related databases to estimate the emissions and spatial distribution of traffic pollutants in Taiwan. Payne-Sturges et al. (2004) compared the measured and modelled exposure levels of VOCs in GIS environment. Many studies have used the spatial analytical function of GIS in studying the atmospheric environment of cities by integrating GIS with atmospheric environmental models (Wu et al. 2011; Ballester et al. 2010; Aguilera et al. 2009; An et al. 2008; Tang and Wang 2007).

According to data collected by the Air Quality Control Company (AQCC) and the Department of Environment (DOE), Tehran is one of the worst cities in the world in terms of air pollution. The studies made by Japan International Co-operation Agency (JICA), among all main emission sources, mobile sources are the largest contributor (about $71 \%$ ) of air pollution in Tehran (United Nations 2003). The main purposes of this study were to perform field measurements and apply statistical analysis procedures to spatially characterize and estimate the variability of hazardous benzene concentrations in an urban area of Tehran. The findings would provide a baseline against which future anthropogenic effects can be evaluated and also be useful for developing proper strategies to control the air quality. This is the first time that such an extensive study about benzene has been carried out in Tehran.

\section{Materials and methods}

The study area

Tehran is located within latitude of $35^{\circ} 40^{\prime} 18^{\prime \prime}$ and longitude of $51^{\circ} 25^{\prime} 27^{\prime \prime}$ with an altitude of $1,191 \mathrm{~m}$ above the mean sea level in a semi-arid region of Iran. The hottest month is July (with mean minimum temperature of $26^{\circ} \mathrm{C}$ and mean maximum temperature of $36{ }^{\circ} \mathrm{C}$ ) and the coldest is January (with mean minimum temperature of $-1{ }^{\circ} \mathrm{C}$ and mean maximum temperature of $8^{\circ} \mathrm{C}$ ). District 1 is situated in the north of Tehran and surrounded by a traffic corridor (Hastaie 2001). The present study aimed at determining and quantifying benzene concentrations in ambient air in different areas in the north of Tehran (District 1). Sampling was conducted at the 33 sites, in 5 categories including roadside (nine sampling stations), busy road (five sampling stations), residential area (eight sampling stations), traffic intersection (seven sampling stations), and outside gas station (four sampling stations) from 14:00 to 17:00 once a week during 5 April 2010-25 March 2011. Samplings were set up at about $1.5 \mathrm{~m}$ above the ground. The sampling stations are shown in Fig. 1 and Table 1.

\section{Sampling strategy}

The sampling stations were selected on the basis of major activities in the region. The road network in this study is $25 \mathrm{~km}$ long. Spatial variability of benzene concentration levels in the ambient air were investigated through 


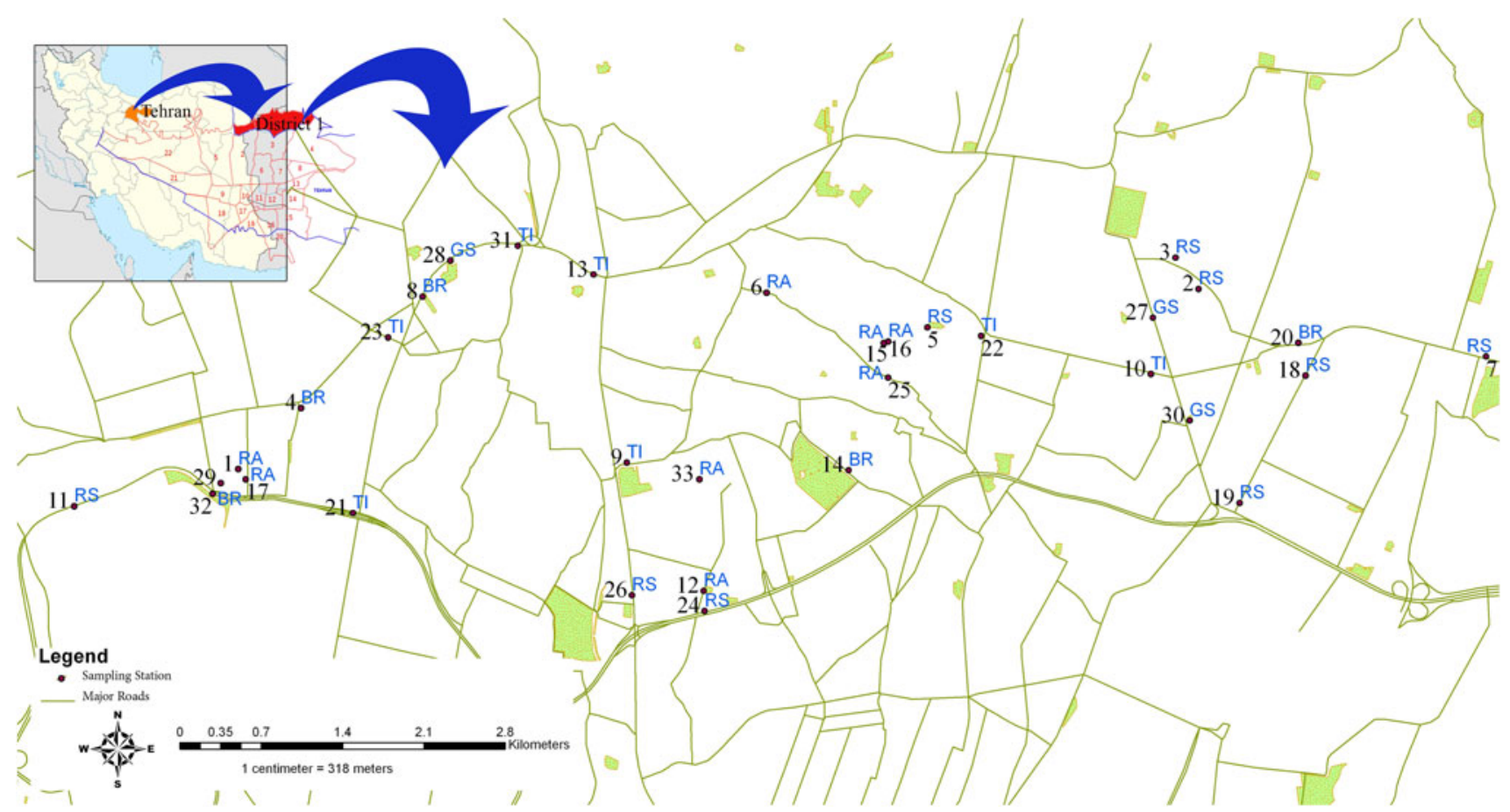

Fig. 1 The location of 33 sampling sites in Tehran, Iran. Individual sampling locations of the study area are assigned as: $R S$ roadside, GS gas station, $R A$ residential area, $T I$ traffic intersection, and $B R$ busy road

measurement at a network of 33 sites. The selected residential areas in this study were located quite far (100-500 m away) from the main roads and had negligible traffic flow. However, the results obtained from the eight residential sampling stations show benzene concentrations in the ambient air. At the roadsides, busy roads, and traffic intersection stations, the air quality is influenced by traffic density, slope of the road, and heavy (truck, buses, etc.) and light duty vehicles. In the outside gas station category, four gas stations with heavy traffic inflow including Aghdaseyeh (ID code $=27$ ), Baghe Ferdos (ID code $=28$ ), Velenjak (ID code $=29$ ), and Pasdaran (ID code $=30$ ) were selected to be monitored and monitoring was carried out 10-20 m away from the gas stations.

Benzene concentrations were measured by a portable Photo Ionization Detector (PID, Model PhoCheck 5000Ex, Ion Science Ltd, UK), which was calibrated by using 100 ppm of isobutene. PhoCheck is an intrinsically safe portable gas-detector, suitable for detection of VOCs by a PID. The PID instrument was placed near the stations, adjacent to the ring-stand holding the sampling device, and the data was recorded at $10-\mathrm{min}$ intervals. The monitoring schedule in all stations followed 3 hourly samples during rush hours. The concentration levels of benzene were observed in a control area, which was a clean room and found to be equal to $0 \mathrm{ppb}$ (PhoCheck+ Instrument User Manual V2.6 2012).
Benzene content of petrol

Benzene is an ordinary component of crude and refined petroleum. The mandatory decrease of lead alkyls in gasoline has led to an increase in the aromatic hydrocarbon content of gasoline to keep up high octane levels and antiknock properties (Tayanc 2000). In urban areas, the benzene content of petrol is an important influential factor in determining benzene concentration level in the air. Generally, petrol production from petrochemical products and consumption of poor quality petrol are contributing to the air pollution crisis in Tehran. At present, two types of petrol with octane numbers of 87 and 95 are being used in the light duty vehicles in Tehran. In line with the objectives of the present study, samples were taken from five gas stations in Tehran and analyzed with gas chromatography (Table 2). According to the results, the mean benzene concentration is $4.26 \mathrm{vol} \%$, whereas in many developed countries it is about $1 \mathrm{vol} \%$.

\section{Inverse distance weight (IDW) model}

The trends of utilizing IDW model were closely analyzed. Tools like GIS and spatial interpolation methods such as IDW have been applied to make use of the sampling data to estimate the ambient air pollutant levels in the unmeasured 
Table 1 Sampling locations in Tehran urban region

\begin{tabular}{|c|c|c|c|c|}
\hline \multirow[t]{2}{*}{ Identification code } & \multirow[t]{2}{*}{ Station name } & \multicolumn{2}{|c|}{ Geographic location } & \multirow[t]{2}{*}{ Situation } \\
\hline & & $x$ & $y$ & \\
\hline 1 & 6 Sharghi-shadavar & 536,831 & $3,961,140$ & Residential area \\
\hline 2 & Aghdaseyeh-golestan & 543,076 & $3,962,312$ & Roadside \\
\hline 3 & Aghdaseyeh-park & 542,925 & $3,962,515$ & Roadside \\
\hline 4 & Alef Sq & 537,239 & $3,961,537$ & Busy road \\
\hline 5 & Andarzgoo-vatanpoor & 541,312 & $3,962,062$ & Roadside \\
\hline 6 & Anjoman koshnevesan & 540,267 & $3,962,288$ & Residential area \\
\hline 7 & Artesh-ozgol & 544,945 & $3,961,872$ & Roadside \\
\hline 8 & Bagh ferdos & 538,028 & $3,962,261$ & Busy road \\
\hline 9 & Bolvarsaba-pol romi & 539,358 & $3,961,183$ & Intersection traffic \\
\hline 10 & Darmangah farmaneyeh & 542,765 & $3,961,758$ & Intersection traffic \\
\hline 11 & Eskan kareghari & 535,763 & $3,960,900$ & Roadside \\
\hline 12 & Ghalandari-park shadi & 539,858 & $3,960,349$ & Residential area \\
\hline 13 & Ghods sq & 539,140 & $3,962,404$ & Intersection traffic \\
\hline 14 & Ghytareyeh & 540,801 & $3,961,133$ & Busy road \\
\hline 15 & Hashemi alley & 541,058 & $3,961,971$ & Residential area \\
\hline 16 & Hosseini alley & 541,028 & $3,961,960$ & Residential area \\
\hline 17 & Jim-4 shargi & 536,879 & 396,1074 & Residential area \\
\hline 18 & Langari-havashenasi & 543,771 & $3,961,748$ & Roadside \\
\hline 19 & Langari-nobonyad & 543,342 & $3,960,920$ & Roadside \\
\hline 20 & Movahed danesh-masjed & 543,724 & $3,961,961$ & Busy road \\
\hline 21 & Park vay & 537,576 & $3,960,854$ & Intersection traffic \\
\hline 22 & Pashazahri-kamraneyeh & 541,662 & $3,962,007$ & Intersection traffic \\
\hline 23 & Pesyan-valiasr & 537,805 & $3,961,997$ & Intersection traffic \\
\hline 24 & Sadr-dastor & 539,864 & $3,960,218$ & Roadside \\
\hline 25 & Salimi alley & 541,057 & $3,961,735$ & Residential area \\
\hline 26 & Shariyati-metro sadr & 539,391 & $3,960,321$ & Roadside \\
\hline 27 & Station 134 aghdaseyeh & 542,780 & $3,962,124$ & Outside gas station \\
\hline 28 & Station 139 bagh ferdos & 538,210 & $3,962,496$ & Outside gas station \\
\hline 29 & Station 148 velenjak & 536,717 & $3,961,050$ & Outside gas station \\
\hline 30 & Station 27 pastaran & 543,017 & $3,961,455$ & Outside gas station \\
\hline 31 & Tajrish Sq & 538,648 & $3,962,592$ & Intersection traffic \\
\hline 32 & Chamran-velenjak & 536,664 & $3,960,981$ & Busy road \\
\hline 33 & Tapeh-ghytareyeh & 539,829 & $3,961,074$ & Residential area \\
\hline
\end{tabular}

Table 2 Benzene content in gasoline (samples taken from five petrol stations in Tehran)

\begin{tabular}{lllll}
\hline Sample 1 & Sample 2 & Sample 3 & Sample 4 & Sample 5 \\
\hline $4.10 \mathrm{vol} \%$ & $4.10 \mathrm{vol} \%$ & $4.47 \mathrm{vol} \%$ & $4.22 \mathrm{vol} \%$ & $4.45 \mathrm{vol} \%$
\end{tabular}

locations. Numerous studies have so far applied IDW to map air pollution levels, among which sulphur dioxide in Istanbul, Turkey (Mulholland et al. 1998; Tolbert et al. 2000), ozone in northern Georgia (Bell 2006), and particulates across the entire USA as well as in Beijing, China can be mentioned (Whitworth et al. 2011). IDW is in fact, a statistical technique normally applied in environmental studies for optimal spatial prediction at unobserved locations. It is very useful when the distribution of the estimated parameters is not a normal one. IDW model is essentially based on the premise that the predictions are in a linear combination of available data. The IDW model formulas are given as Eqs. (1) and (2) (Xie et al. 2011):

$$
\begin{aligned}
& Z(x)=\sum w_{i} z_{i} / \sum w_{i} \\
& w_{i}=d_{i}^{-u}
\end{aligned}
$$

where $Z(x)$ is the predicted value at an interpolated point, $z_{i}$ is the predicted value at a known point, $n$ is the total number of known points used in interpolation, $d_{i}$ is the 
distance between point $i$ and the prediction point, and $w_{i}$ is the weight assigned to point $i$. The greater weighting values are assigned to the values closer to the interpolated point. As the distance increases, the weight decreases; $u$ is the weighting power that decides how the weight decreases as distance increases.

In the adopted approach, spatial regressions of the mean annual and seasonal concentrations were supposed to be a function of time for each location. In the studied area, both major semi-axis and minor semi-axis have been chosen to be equal to $1,500 \mathrm{~m}^{2}$, and the proximity effect of the points in the above-mentioned method has been determined to be 33 points. The optimize value weighting power has been chosen to be 1 . In order to cover the benzene dispersion pattern within the interested area, ArcGIS9.3 software with an additional supporting module, Analyst Geo-statistical (extension), and IDW model have been employed. Moreover, the regression functions, root-mean-square, and the mean values have been calculated, and the graphical output of benzene dispersion in Tehran has been depicted. Notably, the accuracy of the model results has been assessed by the cross-validation tools and SPSS software.

\section{Results and discussion}

High concentration levels of benzene were observed in all samples, and the values were much above the WHO's standard concentration levels (1.56-6.25 ppb). The seasonal and annual averages of total benzene concentrations at different stations are presented in Table 3. GIS tool was employed to predict the benzene concentration levels and IDW interpolation model was chosen as a proper tool for calculations. Consequently, the predicted graphical results of the model were calculated and compared with the measured data in the sampling stations within four seasons. Table 3 shows the seasonal and annual benzene concentration levels measured and predicted by IDW model for 33 stations. To facilitate the interpretation of the simulated maps, each map was divided into three distinct parts, namely I, II, and III, covering western (left side), central and eastern (right side) parts of the map, respectively.

Based on the results shown in Table 2, the benzene dispersion pattern in the spring is illustrated in Fig. 2a, which indicates that the highest benzene concentration levels are within the proximity of four gas stations (GS points shown on the map). It is noteworthy that such points have not affected other stations to a great extent in a way that in the right side and central parts of the studied area, the benzene concentration levels are in the range 0.6-3 ppb.

Obviously, the reduction in traffic flow volume and the higher precipitation rates in this season have played a significant role in the air pollution reduction. The related regression function obtained from IDW model for the spring is as shown in Eq. 3:

$y=0.718 x+2.844$ and $R^{2}=0.828$

As illustrated in Fig. 2b, dispersion of benzene around the gas stations in the summer have affected other areas much more than the spring time, so that the benzene concentrations within the right side of the map, the Farmaniye clinic station (ID code $=10$ ) as a Traffic Intersection (TI) station, are in the range 14-20 ppb. According to the map, it is evident that the residential areas (ID code $=17$ and 1) next to gas station 148 (ID code $=29$ ) have been affected by benzene dispersions. The predicted benzene concentration levels in this residential area are in the range of 9-12 ppb. Higher ambient temperature, which is responsible for the greater gasoline evaporation in the gas stations, can be considered as the main reason of benzene pollution in this season. The related regression function obtained from IDW model for the summer is as shown in Eq. 4:

$y=0.883 x+2.074$ and $R^{2}=0.952$

The benzene dispersion pattern in the fall has mostly been affected by weather conditions and, in particular, inversion phenomenon in this season. As can be seen in Fig. 2c, the residential stations including Anjoman (ID code $=6$ ), Hashemi (ID code $=15$ ), Hoseini (ID code $=16$ ), Salimi (ID code $=25$ ), and Andarzgoo (ID code $=5$ ) have the lowest benzene concentration levels. The concentration level pertaining to these stations lies in the range $0.7-3 \mathrm{ppb}$. The related regression function obtained from IDW model for the fall is shown in Eq. 5:

$y=0.910 x+1.786$ and $R^{2}=0.975$

In the winter, due to the reduction of traffic flow volume in the central area, i.e., Park-Shadi station (ID code $=12$ ), as a station with the lower benzene concentration level, has been added to the predicted concentration pattern in the fall. Referring to Fig. 2d, the left side of the studied area shows an extremely high benzene concentration level, the range of which is between 12 and $18 \mathrm{ppb}$. The related regression function obtained from IDW model for the winter is:

$y=0.884 x+1.740$ and $R^{2}=0.967$

It is evident that the benzene concentration levels in all stations are significantly high. This is mainly due to the lack of an appropriate system for removing and collecting the petrol vapors in the gas stations. To reach a better understanding of the annual benzene dispersion pattern in the studied area, the annual concentration 
Table 3 The seasonal and annual benzene concentration levels measured and predicted by IDW for 33 stations

\begin{tabular}{|c|c|c|c|c|c|c|c|c|c|c|}
\hline \multirow[t]{2}{*}{ Identification code } & \multicolumn{2}{|l|}{ Spring } & \multicolumn{2}{|l|}{ Summer } & \multicolumn{2}{|l|}{ Fall } & \multicolumn{2}{|l|}{ Winter } & \multicolumn{2}{|l|}{ Annual } \\
\hline & Measured & Predicted & Measured & Predicted & Measured & Predicted & Measured & Predicted & Measured & Predicted \\
\hline 1 & 2.53 & 3.73 & 7.04 & 8.99 & 8.98 & 9.68 & 11.29 & 12.11 & 7.46 & 8.63 \\
\hline 2 & 4.27 & 5.37 & 11.46 & 12.17 & 16.11 & 17.34 & 15.64 & 16.35 & 11.87 & 12.81 \\
\hline 3 & 6.07 & 7.41 & 12.14 & 15.26 & 20.13 & 19.24 & 16.40 & 15.82 & 13.69 & 14.43 \\
\hline 4 & 11.67 & 9.18 & 14.84 & 12.94 & 21.87 & 20.43 & 20.56 & 18.67 & 17.23 & 15.31 \\
\hline 5 & 4.33 & 4.88 & 9.87 & 6.56 & 4.61 & 5.32 & 4.82 & 6.38 & 5.91 & 5.79 \\
\hline 6 & 0.40 & 1.86 & 3.54 & 5.98 & 4.75 & 6.91 & 2.74 & 3.28 & 2.86 & 4.51 \\
\hline 7 & 0.73 & 7.58 & 2.96 & 3.53 & 4.14 & 7.01 & 1.67 & 2.09 & 2.38 & 5.05 \\
\hline 8 & 6.43 & 7.47 & 12.10 & 13.25 & 17.99 & 18.94 & 16.81 & 19.68 & 13.33 & 14.84 \\
\hline 9 & 9.80 & 6.27 & 15.88 & 14.49 & 20.26 & 19.35 & 26.39 & 25.15 & 18.08 & 16.32 \\
\hline 10 & 8.34 & 11.13 & 15.98 & 14.86 & 18.81 & 19.35 & 14.65 & 12.67 & 14.45 & 14.50 \\
\hline 11 & 11.90 & 9.96 & 11.86 & 13.93 & 15.57 & 17.17 & 15.18 & 16.94 & 13.63 & 14.50 \\
\hline 12 & 0.00 & 7.26 & 1.23 & 2.52 & 1.92 & 2.75 & 1.99 & 3.37 & 1.28 & 3.98 \\
\hline 13 & 14.67 & 13.26 & 16.36 & 15.72 & 14.52 & 15.54 & 18.65 & 16.5 & 16.05 & 15.26 \\
\hline 14 & 13.27 & 12.35 & 16.00 & 15.56 & 15.98 & 13.45 & 19.50 & 16.18 & 16.18 & 14.39 \\
\hline 15 & 0.47 & 1.53 & 0.43 & 1.61 & 1.28 & 2.53 & 1.18 & 2.73 & 0.84 & 2.10 \\
\hline 16 & 0.50 & 1.47 & 0.96 & 1.14 & 0.89 & 1.81 & 1.19 & 2.7 & 0.88 & 1.78 \\
\hline 17 & 5.30 & 8.96 & 8.64 & 9.67 & 9.86 & 10.58 & 11.25 & 13.67 & 8.76 & 10.72 \\
\hline 18 & 3.10 & 7.06 & 9.36 & 11.09 & 13.59 & 12.81 & 11.00 & 12.07 & 9.26 & 10.76 \\
\hline 19 & 5.53 & 9.34 & 11.54 & 12.58 & 12.45 & 14.69 & 15.76 & 15.28 & 11.32 & 12.97 \\
\hline 20 & 4.17 & 6.58 & 5.63 & 11.67 & 6.86 & 8.71 & 6.84 & 8.84 & 5.87 & 8.95 \\
\hline 21 & 11.74 & 9.13 & 11.71 & 13.04 & 23.08 & 21.94 & 15.44 & 16.67 & 15.49 & 15.20 \\
\hline 22 & 11.40 & 5.62 & 9.37 & 9.76 & 14.33 & 11.05 & 16.45 & 13.53 & 12.89 & 9.99 \\
\hline 23 & 5.93 & 9.77 & 10.06 & 11.77 & 16.73 & 19.03 & 20.41 & 18.11 & 13.28 & 14.67 \\
\hline 24 & 7.63 & 6.09 & 14.74 & 13.181 & 20.12 & 18.88 & 15.12 & 13.11 & 14.40 & 12.82 \\
\hline 25 & 0.00 & 0.49 & 1.10 & 2.74 & 0.98 & 1.49 & 0.86 & 1.59 & 0.74 & 1.58 \\
\hline 26 & 4.30 & 6.43 & 5.01 & 6.33 & 9.44 & 10.36 & 10.54 & 12.81 & 7.32 & 8.98 \\
\hline 27 & 19.17 & 17.18 & 34.64 & 33.51 & 32.44 & 33.86 & 25.79 & 24.47 & 28.01 & 27.26 \\
\hline 28 & 21.10 & 19.13 & 26.10 & 25.79 & 40.85 & 37.58 & 34.48 & 33.06 & 30.63 & 28.89 \\
\hline 29 & 21.30 & 19.58 & 29.53 & 27.19 & 37.53 & 35.15 & 29.85 & 27.59 & 29.55 & 27.38 \\
\hline 30 & 22.63 & 20.25 & 29.97 & 28.08 & 30.18 & 31.32 & 28.62 & 26.87 & 27.85 & 26.63 \\
\hline 31 & 10.21 & 10.84 & 11.62 & 12.65 & 13.63 & 15.6 & 23.16 & 24.84 & 14.65 & 15.98 \\
\hline 32 & 13.88 & 14.29 & 16.06 & 20.32 & 19.67 & 20.9 & 16.93 & 18.22 & 16.63 & 18.43 \\
\hline 33 & 0.20 & 1.39 & 3.32 & 6.02 & 5.23 & 8.88 & 5.57 & 7.59 & 3.53 & 5.97 \\
\hline
\end{tabular}

levels obtained from 33 stations, similar to the abovementioned patterns, were simulated for District 1 of Tehran in a GIS environment. Figure 3 indicates that the highest benzene concentration levels occur at the eastern half part of the studied area and the benzene concentration levels for the stations 13,21,29, 28, and 32 are in the range 16-32 ppb. Thus, the eastern half part can be labeled as the most polluted area in the present study. The lowest benzene concentration levels are obtained from the central part of the studied area, i.e., stations $2,3,5,6,12$, and 33 , where covers a congested residential area. The above-mentioned explanation, no gas station can be found in part II, which accounts for the least annual benzene pollution level. Benzene concentration levels in this area fall in the range 0.6-4 ppb. Similar to part I, the higher benzene pollution levels occur in part III. However, the benzene concentration level decreases in the northern parts, due to the reduction of traffic flow volume and being far away from the pollution sources. In particular, Ozgol (ID code $=7$ ) and Langary (ID code $=19$ ) stations experience the lower benzene pollution levels of $0.9-5 \mathrm{ppb}$. The related annual regression function obtained from IDW model for 33 stations is: 


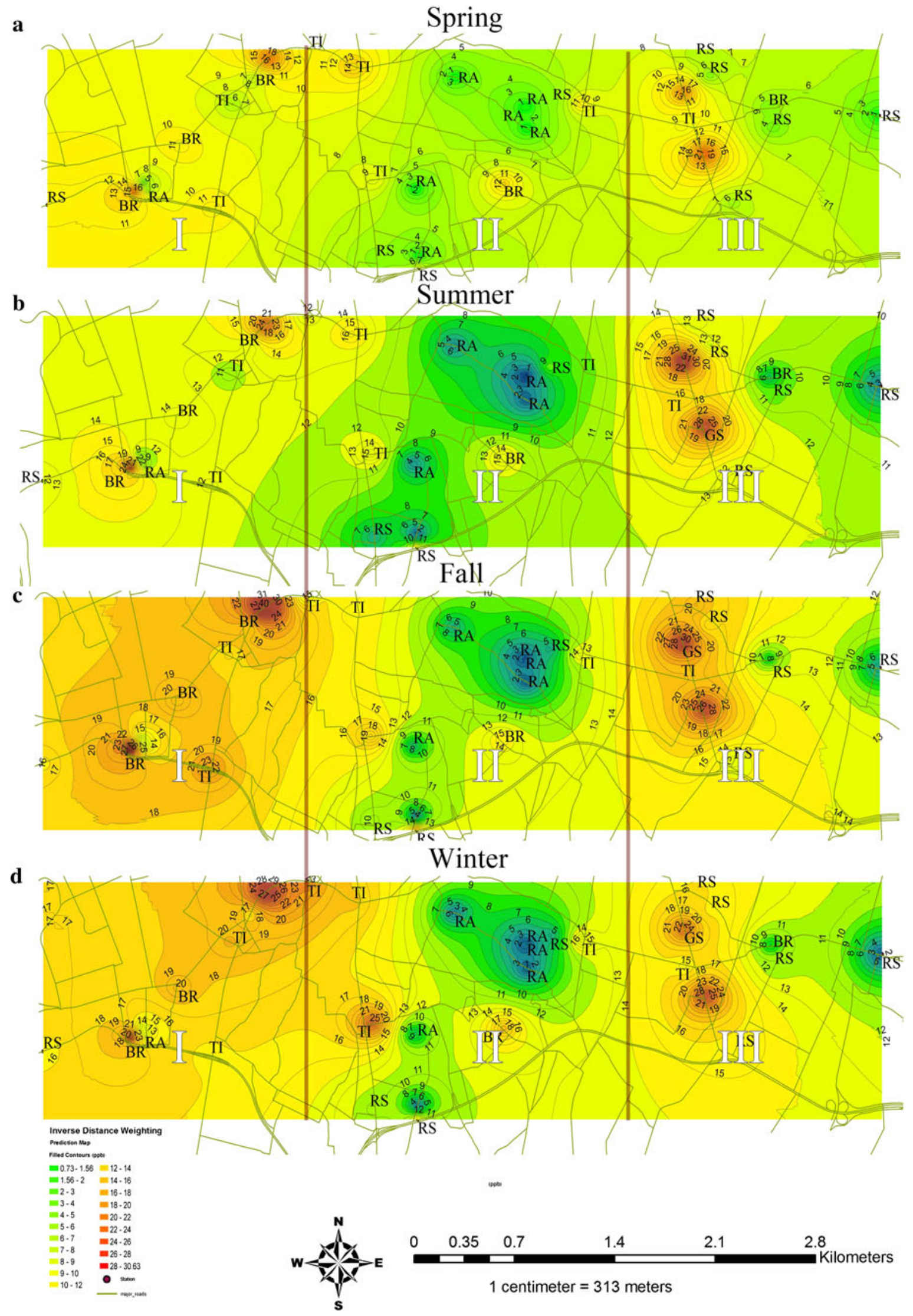

Fig. 2 Seasonal benzene concentration levels predicted by GIS for 33 main stations 


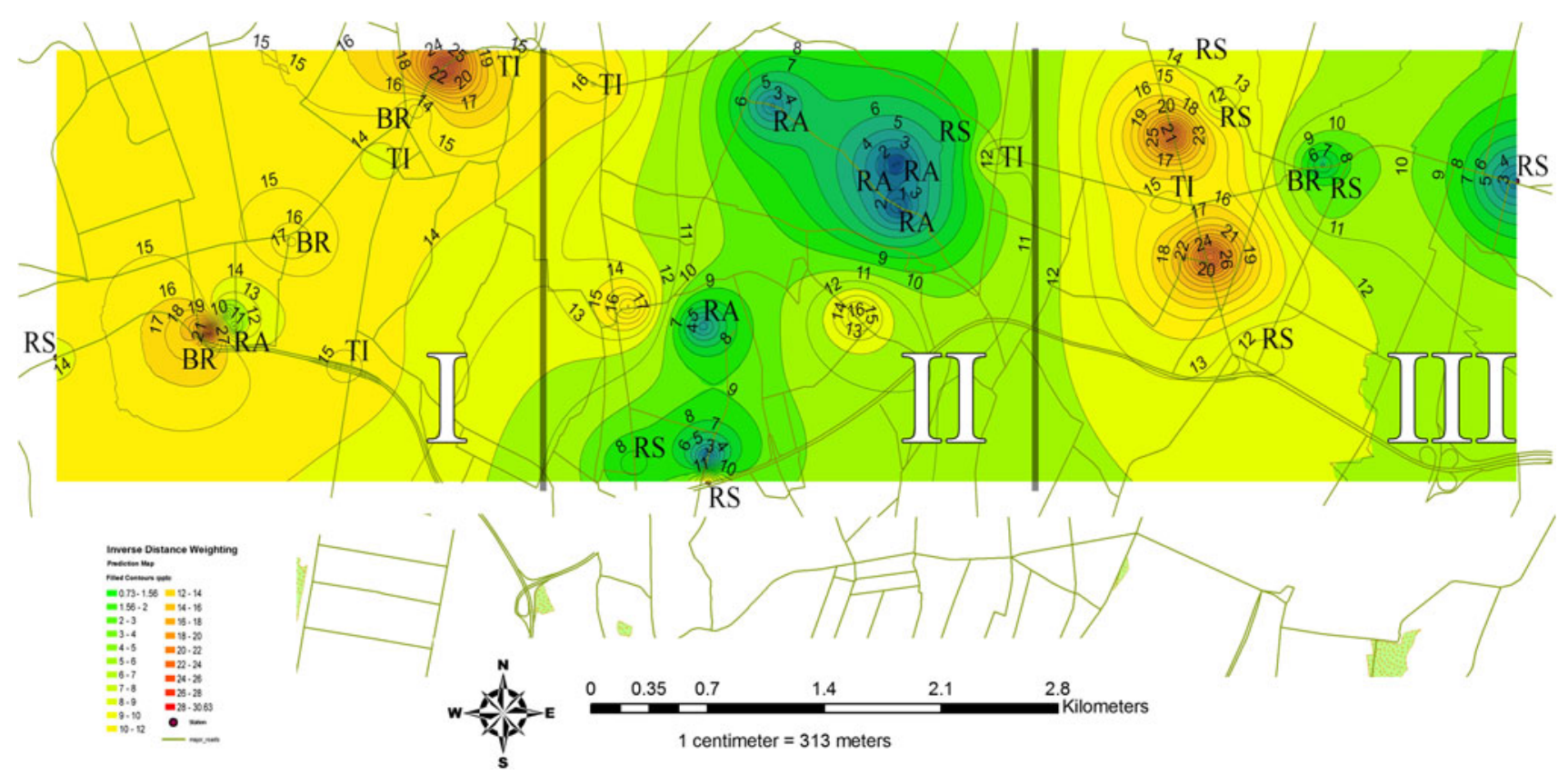

Fig. 3 Annual benzene concentration levels predicted by GIS for 33 main stations

Fig. 4 Monthly variation of benzene concentrations in the ambient air of Tehran

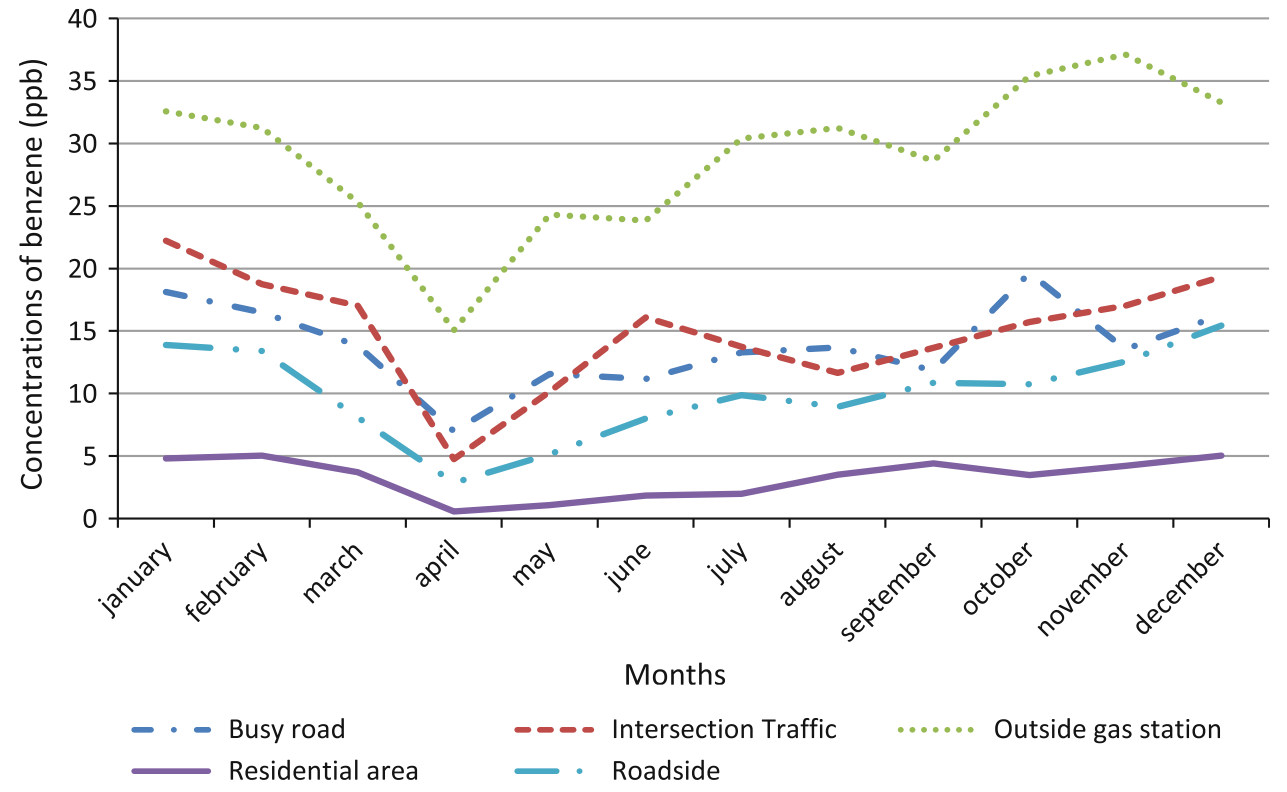

in many other cities (Ho et al. 2004). Benzene concentrations reach to a maximum level in the winter due to the higher atmospheric stability conditions, and a minimum level in the summer. Since more sunlight and higher temperatures lead to higher chemical removal reaction rates, the chemical removal of benzene by $\mathrm{OH}$ radicals acts faster in the summer than in the winter (Ho et al. 2004; Parra et al. 2009). 
Table 4 The average concentrations of benzene for five main groups in four seasons

\begin{tabular}{llllllrrrr}
\hline & $n$ & Spring & SD & Summer & SD & Fall & SD & Winter & SD \\
\hline Busy road & 5 & 9.88 & 4.34 & 12.93 & 4.38 & 16.47 & 5.79 & 16.13 & 5.44 \\
Intersection traffic & 7 & 10.30 & 2.75 & 13.00 & 3.00 & 17.34 & 3.53 & 19.31 & 4.31 \\
Outside gas station & 4 & 21.05 & 1.43 & 30.06 & 3.51 & 35.25 & 4.83 & 29.68 & 3.62 \\
Residential area & 8 & 1.31 & 1.96 & 3.28 & 3.30 & 4.09 & 3.88 & 4.36 & 4.76 \\
Roadside & 9 & 5.32 & 3.13 & 9.88 & 3.70 & 12.91 & 5.92 & 11.79 & 5.33 \\
\hline
\end{tabular}

Table 5 Concentrations (ppb) of benzene reported from several worldwide sites

\begin{tabular}{llll}
\hline City & $\begin{array}{l}\text { Benzene concentration } \\
(\mathrm{ppb})\end{array}$ & Location & Reference \\
\hline London, UK & 6.25 & Busy road & Derwent et al. (1995) \\
Tehran, Iran & 13.85 & Busy road & Present study \\
Tehran, Iran & 29.01 & Outside gas station & Present study \\
Tehran, Iran & 3.26 & Residential area & Present study \\
Alberta, Canada & 0.94 & Roadside & Heeb et al. (1999) \\
Athens, Greece & 5.00 & Roadside & Moschonas and Glavas (1996) \\
Port Alegre, Brazil & 7.81 & Roadside & Grosjean et al. (1998) \\
Tehran, Iran & 9.97 & Roadside & Present study \\
Shirogane, Japan & 0.25 & Roadside & Laowagul and Yoshizumi (2009) \\
Tehran, Iran & 14.98 & Traffic intersection & Present study \\
El Qualaly, Cairo & 13.44 & Traffic zone & Abu-Allaban and Lowenthal (2002) \\
Delhi, India & 27.1 & Traffic zone & Khillare et al. (2008) \\
Pamplona, Spain & 0.89 & Residential area & Parra et al. (2009) \\
Germany & $0.385-0507$ & Residential area & Schneider et al. (2001) \\
\hline
\end{tabular}

The least benzene concentration level was associated to the spring, which is almost evident in all five main categories (compared with the other stations). This is mainly related to seasonal benzene concentration variation and Iranian New Year holidays, when there is a considerable decline in traffic flow volume in the study area.

Referring to the results presented in Table 4, the mean benzene concentrations for the five main groups in four seasons of the year were calculated using Microsoft Excel. The results showed that the mean annual benzene concentrations were $13.58 \pm 0.738 \mathrm{ppb}$ for the roads with heavy traffic, $14.98 \pm 0.689 \mathrm{ppb}$ for the traffic intersections, $29.01 \pm 1.411 \mathrm{ppb}$ for the vicinity of the gas stations, $3.26 \pm 1.17 \mathrm{ppb}$ for the residential areas, and $9.97 \pm 1.319 \mathrm{ppb}$ for the roadsides. It should be noted that the number of samples in the all 5 categories were 12 in each season, thereby amounting to 48 samples in a year. The observed benzene concentration levels at the sampling stations have been compared to the values reported from other parts of the world. The concentrations of benzene registered in this study were in the range of those found for benzene in Delhi and Cairo. European cities show generally lower benzene concentration levels, as those found in Germany and a number of British and Spain cities, while large cities are characterized by higher benzene pollution levels, such as those found in India and Iran (Table 5). In Shirogane (Japan), the benzene concentrations were found to be lower than those in Tehran (Abu-Allaban et al. 2002; Grosjean et al. 1998; Moschonas and Glavas 1996; Heeb et al. 1999; Derwent et al. 1995; Khillare et al. 2008; Schneider et al. 2001).

\section{Conclusion}

Based on the measured data in this study, the gas stations and traffic flow level are two main reasons for high benzene concentration levels in this study. The overall average 
pattern of benzene concentration levels were consistent across the five categories. The identified benzene concentration levels in a decreasing order were include: vicinity of the gas stations $>$ traffic intersection $>$ busy road $>$ roadside $>$ residential area. According to the results, the annual concentration levels of benzene was $13.85 \mathrm{ppb}$ for roads with heavy traffic flow, 14.98 ppb for traffic intersections, $29.01 \mathrm{ppb}$ for the vicinity of the gas stations, $3.26 \mathrm{ppb}$ for residential areas, and $9.97 \mathrm{ppb}$ for roadsides. In all stations, the measured average benzene concentration levels in the summer (13.83 ppb) were lower than those found in the winter $(16.28 \mathrm{ppb})$. It is evident that the benzene concentration level in the vicinity of the gas stations is significantly high, which is mainly due to the lack of a system for removing and collecting the petrol vapors within the gas stations. The annual benzene concentration level in the vicinity of the gas stations is $29.01 \mathrm{ppb}$ and the measurement station distance from the gas station was about $10 \mathrm{~m}$. It should be mentioned that within the gas station and close to the gas pumps, the high levels of benzene concentrations have been detected with some samples including the range 110-240 ppb. Unfortunately, in establishment of the gas stations, distance to the residential areas, and the heavy traffic flows of the studied area have not been considered. Also, in Tehran, the concentration levels of VOCs, including benzene, is far above the standard concentration levels, which is mainly due to the poor quality of gasoline and lack of a standard system for controlling gasoline vapors and refusal of utilizing proper catalytic converters. As mentioned earlier in the introduction, the benzene content level of gasoline should not exceed than $1 \%$ in volume. All members of European Union have been obligated to reduce the benzene content level of gasoline to less than 1 vol\% since January 2000 and benzene content in all USA gasoline will be reduced to $0.62 \mathrm{vol} \%$ to comply with the Mobile Sources Air Toxics Rule (Official Journal of the European Communities L 313 2000; United States Federal Register 2007). However, in Iran, the gasoline contains benzene concentration levels of about 4-5 vol\%.

Normally, preventive and controlling measures can be the principal factors to minimize the benzene vapor emission in the atmosphere. According to the obtained results, the annual benzene concentration levels in Tehran air, if optimistic estimated, is 2-20 times more than the International standard levels (1.56 ppb). Therefore, gasoline quality improvement, including benzene minimization to less than $1 \mathrm{vol} \%$, seems to be the first priority to control the benzene emissions in the air. The results from this study indicate that the high levels of benzene concentrations are capable of increasing the probability of cancer risk within the boundaries of Tehran. It is worth mentioning that the continual sampling and employing the GIS system and periodic benzene dispersion modeling within the urban areas are the most important measures for making decisions about places like Tehran.

Acknowledgments The authors would like to thank Department of Environment and Energy, Islamic Azad University, Science and Research Branch for the technical assistance and all constructive supports.

\section{References}

Abbaspour M, Soltaninejad A (2004) Design of an environmental assessment model on the effect of vehicle emission in greater Tehran on air pollution with economic sensitivity. Int $\mathrm{J}$ Environ Sci Technol 1(1):27-38

Abu-Allaban M, Gertler AW, Lowenthal DH (2002) A preliminary apportionment of the sources of ambient PM and VOCs in Cairo. Atmos Environ 36:5549-5557

Aguilera I, Guxens M, Garcia-Esteban R, Corbella T, Nieuwenhuijsen MJ, Foradada CM, Sunyer J (2009) Association between GISbased exposure to urban air pollution during pregnancy and birth weight in the INMA Sabadell cohort. Environ Health Perspect 117:1322-1327

An X, Ma A, Liu D (2008) A GIS-based study for optimizing the total emission control strategy in Lanzhou City. Environ Model Assess 13:491-501

Anabtawi JA, Ali SA, Ashraf Ali M (1996) Impact of gasoline and diesel specifications on the refining industry. Energy Sources Part A 18(2):203-214

Bahrami AR, Edwards JW (2006) Evaluation of benzene exposure in adults and urinary s-phenylmercapturic acid in children living in Adelaide, South Australia. Int $\mathrm{J}$ Environ Sci Technol 3(2):113-117

Ballester F, Estarlich M, Iniguez C, Llop S, Ramon R, Esplugues A, Lacasana M, Rebagliato M (2010) Air pollution exposure during pregnancy and reduced birth size: a prospective birth cohort study in Valencia, Spain. Environ Health 9:6-15

Batterman S, Hatzivasilis G, Jia C (2006) Concentrations and emissions of gasoline and other vapors from residential vehicle garages. Atmos Environ 40:1828-1844

Bell ML (2006) The use of ambient air quality modeling to estimate individual and population exposure for human health research: a case study of ozone in the northern Georgia region of the United States. Environ Int 32:586-593

Cocheo V, Sacco P, Boaretto C, De Saeger E, Ballesta PP, Skov H, Goalen E, Gonzalez N, Caracena AB (2000) Urban benzene and population exposure. Nature 404:141-142

Colls JJ, Micallef A (1997) Towards better human exposure estimates for setting air quality standards. Atmos Environ 31:4253-4254

Derwent RG, Middletown DR, Field RA, Goldstone ME, Lester JN, Perry R (1995) Analysis an interpretation of air quality data from an urban air quality data from an urban roadside location in central London over the period from July 1991-July 1992. Atmos Environ 29:923-946

Grosjean E, Rasmuseen RA, Grosjean D (1998) Ambient levels of gas phase pollution in Porto Alegre. Brazil Atmos Environ 32(20):3371-3379 
Guo H, So KL, Simpson IJ, Barletta B, Meinardi S, Blake DR (2007) C1-C8 VOCs in the atmosphere of Hong Kong: overview of atmospheric processing and source apportionment. Atmos Environ 41:1456-1472

Han X, Naeher LP (2006) A review of traffic-related air pollution exposure assessment studies in the developing world. Environ Int 32:106-120

Hastaie P (2001) Air Pollution Countermeasures in Tehran. Available at http://siteresources.worldbank.org/inturbantransport/Resources/ hastaie.pdf. Accessed 1 Mar 2001

Heeb NV, Forss AM, Bach C (1999) Fast and quantitative measurement of benzene, toluene and $\mathrm{C} 2$ benzene's in an automotive exhaust during transient engine operation with and without catalytic exhaust treatment. Atmos Environ 33:205-215

Ho KF, Lee SC, Guo H, Tsai WY (2004) Seasonal and diurnal variations of volatile organic compounds (VOCs) in the atmosphere of Hong Kong. Sci Total Environ 322:155-166

Hsieh LT, Yang HH, Chen HW (2006) Ambient BTEX and MTBE in the neighborhoods of different industrial parks in Southern Taiwan. J Hazard Mater 128:106-115

International Agency for Research on Cancer (IARC) (2012). Available at http://monographs.iarc.fr/eng/Monographs/vol29/volume29.pdf. Accessed 26 June 2012

Jafari HR, Ebrahimi S (2007) A study on risk assessment of benzene as one of the VOCs air pollution. Int J Environ Res 1(3):214-217

Karner AA, Eisinger DS, Niemeier DA (2010) Near-roadway air quality: synthesizing the findings from real-world data. Environ Sci Technol 44(14):5334-5344

Khillare PS, Rafiqul Hoque R, Shridhar V, Agarwal T, Balachandran S (2008) Temporal variability of benzene concentration in the ambient air of Delhi: a comparative assessment of pre- and postCNG periods. J Hazard Mater 154:1013-1018

Khoder MI (2007) Ambient levels of volatile organic compounds in the atmosphere of greater Cairo. Atmos Environ 41:554-566

Laowagul W, Yoshizumi K (2009) Behaviour of benzene and 1,3butadiene concentrations in the urban atmosphere of Tokyo, Japan. Atmos Environ 43:2052-2059

Lin M, Lin Y (2002) The application of GIS to air quality analysis in Taichung City, Taiwan. Environ Model Softw 17:11-19

Meinardi S, Nissenson P, Barletta B, Dabdub D, Rowland FS, Blake DR (2008) Influence of the public transportation system on the air quality of a major urban center. A case study: Milan, Italy. Atmos Environ 42:7915-7923

Moschonas N, Glavas S (1996) C-C hydrocarbons in the atmosphere of Athens, Greece. Atmos Environ 30:2769-2772

Mulholland JA, Butler AJ, Wilkinson JG, Russell AG, Tolbert PE (1998) Temporal and spatial distributions of ozone in Atlanta: regulatory and epidemiologic implications. J Air Waste Manag Assoc 48:418-426

Obee AJ, Griffin EC, Wright RD (1998) Using a GIS to overcome data adversity: industrial air pollution risk modeling in Tijuana, Mexico. Photogramm Eng Rem S 64(11):1089-1096

Official Journal of the European Communities L 313 (2000) Directive 2000/69/EC relating to limit values for benzene and carbon monoxide in ambient air. Available at http://rod.eionet.europa. eu/instruments/518. Accessed 21 Dec 2012

Ortiz E, Alemon E, Romero D, Arriaga JL, Olaya P, Guzman F, Rios C (2002) Personal exposure to benzene, toluene and xylene in different microenvironments at the Mexico City metropolitan zone. Sci Total Environ 287:241-248

Parra MA, Elustondo D, Bermejo R, Santamaría JM (2009) Ambient air levels of volatile organic compounds (VOC) and nitrogen dioxide $\left(\mathrm{NO}_{2}\right)$ in a medium size city in Northern Spain. Sci Total Environ 707:999-1009

Payne-Sturges DC, Burke TA, Breysse P, Diener-West M, Buckley TJ (2004) Personal exposure meets risk assessment: a comparison of measured and modeled exposures and risks in an urban community. Environ Health Perspect 112:589-598

Perry R, Gee IL (1993) Vehicle emission in relation to fuel composition. Imperial College, London

PhoCheck + Instrument User Manual V2.6 (2012). Available at http://www.ionscience.com/assets/files/manuals/PhoCheck+\%20 Manual\%20V2.6\%281\%29.pdf. Accessed 25 Feb 2012

Rao PS, Ansari MF, Gavane AG, Pandit VI, Nema P (2008) Seasonal variation of toxic benzene emissions in petroleum refinery. Environ Monit Assess 128:323-328

Schifter I, Diaz L, Lopez Salinas E (2006) A predictive model to correlate fuel specifications with on-road vehicles emissions in Mexico. Environ Sci Technol 40(4):1270-1279

Schneider P, Gabefügi I, Rochter K, Wölke G, Schnelle J, Wichmann HE (2001) Indoor and outdoor BTX levels in German cities. Sci Total Environ 267:41-51

Skov H, Hansen AB, Lorenzen G, Andersen HV, Lofstrom P, Christensen CS (2001) Benzene exposure and the effect of traffic pollution in Copenhagen Denmark. Atmos Environ 35:24632471

Som D, Dutta C, Chatterjee A, Mallick D, Jana TK, Sen S (2007) Studies on commuters' exposure to BTEX in passenger cars in Kolkata, India. Sci Total Environ 372:426-432

Tang UW, Wang ZS (2007) Influences of urban forms on trafficinduced noise and air pollution: results from a modelling system. Environ Model Softw 22:1750-1764

Tayanc M (2000) An assessment of spatial and temporal variation of sulphur dioxide levels over Istanbul, Turkey. Environ Pollut 107:61-69

Theakston EdF (2000) Air quality guidelines for Europe, 2nd edn. World Health Organization Regional Publications, Denmark (European series No 91)

Theloke J, Friedrich R (2007) Compilation of a database on the composition of anthropogenic VOC emissions for atmospheric modelling in Europe. Atmos Environ 41:4148-4160

Tolbert PE, Mulholland JA, MacIntosh DL, XU F, Daniels D, Carlin BP, Devine OJ, Klein M, Dorley J, Butler AJ, Nordenberg DF, Frumkin H, White RP (2000) Air quality and pediatric emergency room visits for asthma Atlanta, Georgia, USA. Am J Epidemiol 151:798-810

United Nations (2003) United Nations, cities and sustainable development: lessons and experiences from Asia and by United Nations economic and social commission for Asia and the Pacific, vol 4. United Nations, New York, p 108

United States Federal Register (2007) Control of hazardous air pollutants from mobile sources. Fed Reg 72(37):8427-8476

Vlachokostas CH, Chourdakis E, Moussiopoulos N (2011) Combining regression analysis and air quality modelling to predict benzene concentration levels. Atmos Environ 45:2585-2592

Wang F, Costabile F, Liu F, Hong W, Fang D (2010) Ambient BTX measurements in Suzhou, China. Environ Monit Assess 168:21-31

Whitworth KW, Symanski E, Lai D, Coker AL (2011) Kriged and modeled ambient air levels of benzene in an urban environment: an exposure assessment study. Environ Health. doi:10.1186/1476069X-10-21

Wilhelm M, Ritz B (2003) Residential proximity to traffic and adverse birth outcomes in Los Angeles County, California, 1994-1996. Environ Health Perspect 111:207-216 
Wu J, Wilhelm M, Chung J, Ritz B (2011) Comparing exposure assessment methods for traffic-related air pollution in an adverse pregnancy outcome study. Environ Res 111:685-692
Xie Y, Chen T, Lei M, Yang J, Jun Guo Q, Song B, Zhou X (2011) Spatial distribution of soil heavy metal pollution estimated by different interpolation methods. Chemosphere 82:468-476 